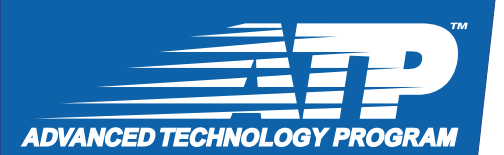

ADVANCEDTECHNOLOCY PROCRAM

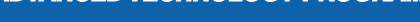

\title{
Advanced Technology Program
} Information Infrastructure for Healthcare Focused Program: A Brief History

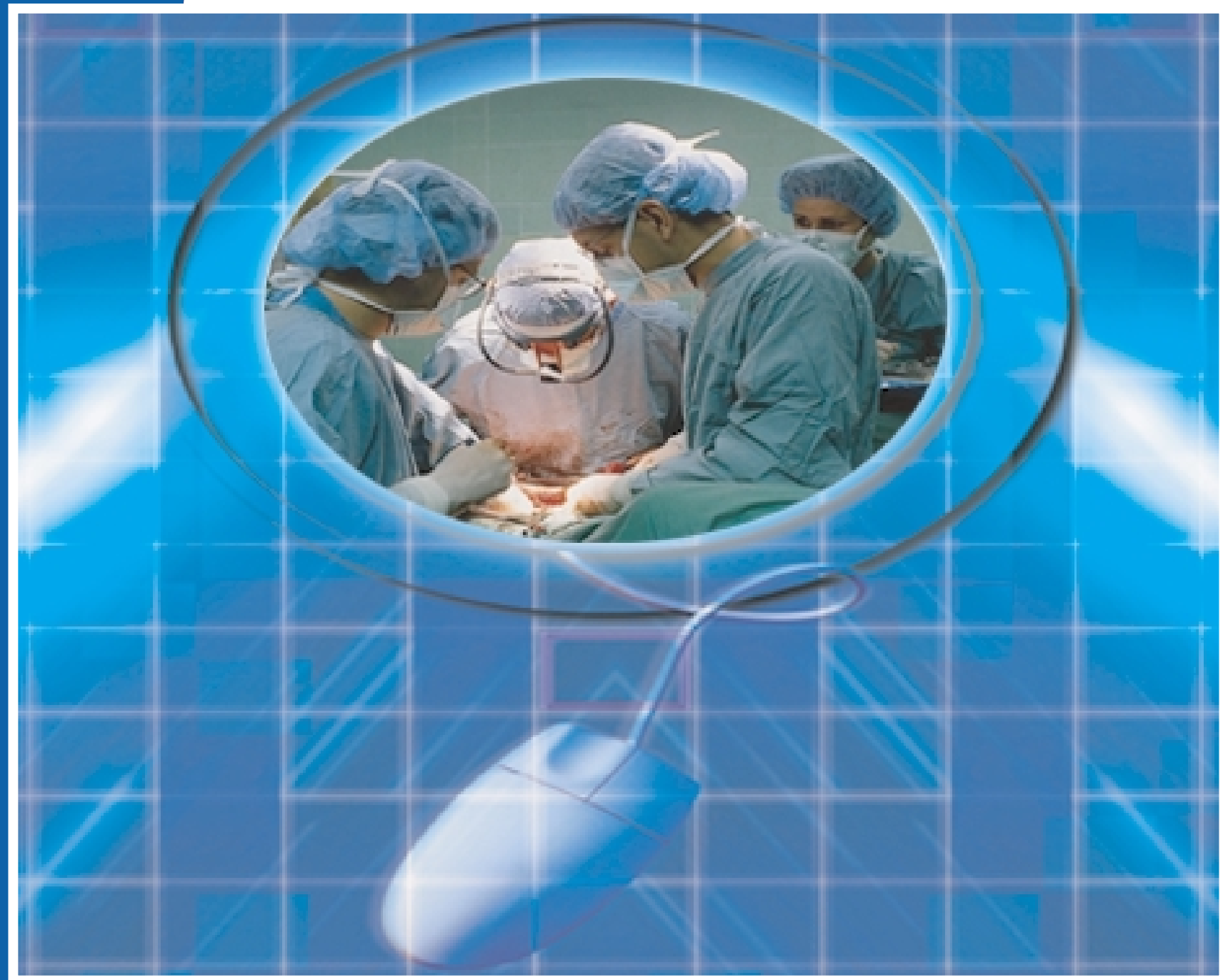

February 2000 
U.S. DEPARTMENT OF COMMERCE Technology Administration

National Institute of Standards and Technology
Economic Assessment Office Advanced Technology Program

Gaithersburg, Maryland 20899

NISTIR 6477

\section{Advanced Technology Program Information Infrastructure for Healthcare Focused Program: A Brief History}

\section{Bettijoyce Lide and Richard N. Spivack}

February 2000

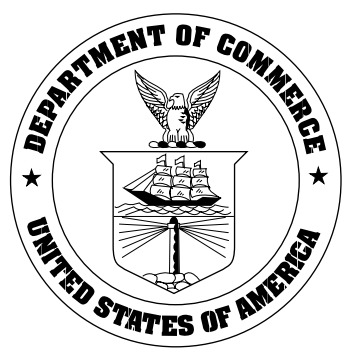

U.S. DEPARTMENT OF COMMERCE

William M. Daley, Secretary

TECHNOLOGY ADMINISTRATION

Dr. Cheryl L. Shavers, Under Secretary of Technology

NATIONAL INSTITUTE OF STANDARDS AND TECHNOLOGY

Raymond G. Kammer, Director 


\section{Table of Contents}

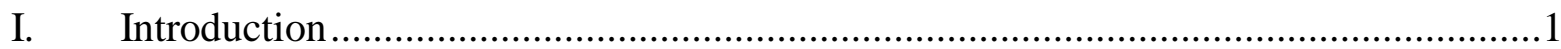

II. Information Technology and Medicine .........................................................2

III. ATP and Focused Programs ............................................................................

IV. Information Infrastructure for Healthcare Focused Program .................................5

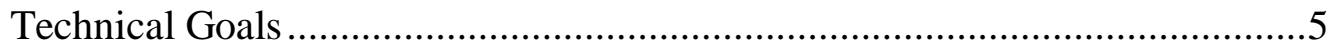

Business Goals ....................................................................................6

V. IIH Focused Program Project Selection Process ................................................. 7

VI. IIH Focused Program Awardees ............................................................

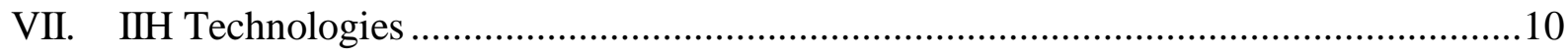

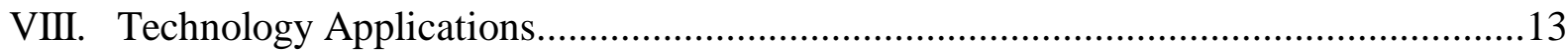

IX. New Format for Proposal Solicitation, Review, and Selection .............................. 14

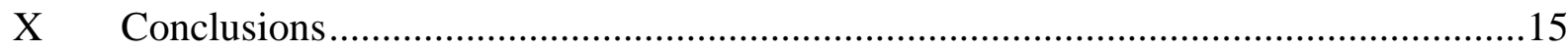

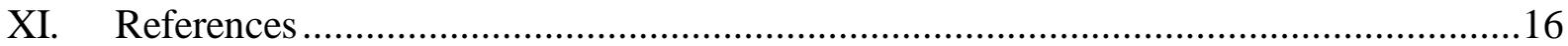




\section{Advanced Technology Program Information Infrastructure for Healthcare Focused Program : A Brief History Bettijoyce Lide and Richard N. Spivack ${ }^{l}$}

\section{Introduction}

This paper illustrates how a "bottom-up" model of a civilian technology program works by recounting the story of the "genesis" of the Advanced Technology Program's (ATP) ${ }^{2}$ Information Infrastructure for Healthcare (IIH) focused program. The IIH program began with an initial exchange of ideas among members of the private and public sectors (industry's submission of "white papers",; workshops conducted by the ATP; meetings held between individuals from both groups) to identify those technologies necessary for the development of a national information infrastructure in healthcare. A discussion of the ATP "white paper" process ${ }^{4}$ notes differences that existed between what the ATP had hoped to gain through this method and how the private sector responded. A statistical description of the participants, a discussion of the ATP review and selection process as well as an overview of selected funded projects is included.

The Advanced Technology Program at the National Institute of Standards and Technology (NIST) is a cost-sharing program designed to partner the federal government with the private sector to further both the development and dissemination of "high-risk" technologies which offer the potential for significant, broad-based economic benefits for the nation. In this program, industry proposes research projects to the ATP to be judged in competitions for funding based upon both the technical and economic/business merits of the proposal. From 1990 through 1998, the ATP held "General" competitions each year open to all technologies. From 1994 through 1998, the ATP awarded most of its funding through "focused-program" competitions in which a suite of projects was funded to mobilize technology to address a particular problem. Thirty focused program competitions were held, each with a unifying set of project goals.

Starting with fiscal year 1999, ATP shifted to a hybrid form of competition-an "Open Competition"- -in which ATP performs its outreach with industry much as it did under focused program competitions, but with a single competition open to all, within this open competition, several selection boards were used, each with its own technology focus. This change was made

\footnotetext{
${ }^{1}$ Bettijoyce Lide is the Program Manager for the IIH focused program. Richard N. Spivack is an economist in the Economic Assessment Office of the ATP.

${ }^{2}$ The ATP statute originated in the Omnibus Trade and Competitiveness Act of 1988 (Pub. L. 100-418, 15 U.S.C. 278n) and was amended by the American Technology Preeminence Act of 1991 (Pub. L. 102-245)

${ }^{3}$ A mechanism by which industry conceptualizes the problems it is having difficulty addressing, including the kinds of technological barriers that must be overcome.

${ }^{4}$ It should be noted that there is a difference between the individual white papers submitted by industry members, citizens, university professors, etc., and the comprehensive program definition white papers created by ATP program managers from the individual papers. A program manager would synthesize the information supplied by the various submitters of individually generated white papers into a comprehensive program definition white paper prepared for submission to the NIST and ATP Directors for approval of launching a focused program.

${ }^{5}$ High risk technologies are defined as technical challenges " that should result in a dramatic change in the future direction of technology. Risk may be high in developing single innovations, integrating technologies, or both." ATP Proposal Preparation Kit, U.S. Department of Commerce, NIST, November 1999, p. 29.
} 
primarily because the industry demand for focused programs outstripped ATP's budgetary ability to respond.

This paper discusses one particular focused program, the Information Infrastructure for Healthcare (IIH) focused program, initiated in 1994 amid a nationwide discussion of the rising costs of healthcare and the quality of care offered.

"Focused programs are defined as multi-year efforts aimed at specific, well-defined technology and business goals. These programs, which involve the parallel development of a suite of interlocking $R \& D$ projects, tackle major technology problems with high payoff potential which cannot be solved by an occasional project coming through the general competition. By managing groups of projects that complement and reinforce each other, the ATP can have the greatest possible impact on the economy."6

The objective of the ATP IIH focused program was to develop the information infrastructure technologies needed to cut dramatically the $20 \%$ of the United States' $\$ 1$ trillion healthcare cost spent on paperwork, and to improve the quality and flexible delivery of care by faster broad access to better information. ATP awards for research made possible new technological capabilities in firms, allowing them to introduce advanced functionalities into their existing IIH products and to introduce new products. These awards allowed the smallest firms to extend their limited resources and gave them additional ability to overcome research barriers impeding the attraction of private venture capital funding. It encouraged large companies to pursue enabling, high-risk research and development in a time of tight discretionary budgets.

\section{Information Technology and Medicine}

There are several incentives for the creation of the field of healthcare information science, from within the medical profession to improve diagnosis and treatment, and from government and industry to reduce costs, although all spheres share each of these motivations to some degree. Nevertheless, medicine is widely perceived to lag other areas in the degree to which computer hardware and software have been applied to these tasks. ${ }^{7}$ Initially the field was "tool-driven" in that people saw specific problems that computers could solve, such as managing patient data. Many saw the limitations of human performance (human error in decision making, error in the interpretation of x-rays), and this provided an incentive for their work in informatics. Some others came to the field from an examination of the information required in medicine and how it was acquired and managed. And still others were introduced to medical informatics from an interest in technology - the medical field being one of many areas to which computer technology could be applied.

The past several years have witnessed a paradigm shift in the way this country delivers healthcare to its people. Managed care, legislation, and consolidation have worked to redefine the relationship between patient and physician. Managed care has provided the impetus to seek

\footnotetext{
${ }_{7}^{6}$ See the ATP web page http://www.atp.nist.gov

7 "Health Security: The President's Report to the American People." The White House Domestic Policy Council, 1993. P. 12.
} 
ways to increase the quality of results, to be accountable for outcomes, to provide accurate measures of success, and to accomplish all of these with lower costs. ${ }^{8}$ At the interface of medicine, science, and technology, medical informatics de-emphasizes the computer and places more emphasis on the nature of the field to which computations are applied, for example, recordkeeping; the study of the nature of medical information itself; and the storage, retrieval, and optimal use of biomedical information, data, and knowledge for problem solving and decision making. ${ }^{9}$

In response to changing economic conditions, which have created conditions in which technology could serve as a strong agent for change in how healthcare is delivered, there has been a consolidation of healthcare facilities. The report of a special committee under the Domestic Policy Council ${ }^{10}$ identified an opportunity for computer technologies to make a significant impact in the healthcare sector of the economy which had lagged behind other sectors in adoption rates, and it identified an opportunity for a public/private initiative to make a difference. The Clinton Healthcare Reform initiative contributed to a heightened awareness of the issues involved. The level of public awareness generated helped shape the context within which industry and ATP developed the IIH focused program.

\section{ATP and Focused Programs}

In 1993, as a first step in establishing a structured dialogue with industry, ATP issued a call for "white papers". Of course, "industry" is not monolithic. In fact, white papers are submitted by companies, individuals with companies, associations of companies, university professors, members of other organizations, and private citizens without organizational affiliation. Focused programs were introduced during a period of budgetary increases which allowed for targeted opportunities for funding as well as a general competition each year for those proposals outside the scope of announced focused areas. Between the end of 1993 and the beginning of 1994, 920 white papers covering a range of technologies were submitted and sorted by a technology taxonomy. Of this total, approximately two dozen white papers addressing healthcare issues were received, providing both scope and technical detail. Some were submitted by large consortia, which greatly increased the number of participating organizations. These offered a comprehensive roadmap for the ATP in developing a partnership with industry. The white paper process provided a place for people to share their ideas and an opportunity for the ATP to more clearly define the goals of the focused program. The white papers submitted to the ATP address a set of published criteria, namely: technical ideas; economic benefit; industry commitment; and, need for ATP.

Upon receipt of the first batch of white papers and their grouping by taxonomy, the ATP Director assigned program managers ${ }^{11}$ to define possible focused programs, and charged each with additional development of the scope of the proposed programs by furthering the relationship already established with the private sector. The program manager for the IIH focused program

\footnotetext{
8 “Advanced Technology Program: Information Infrastructure for Healthcare (95-10).” U.S. Department of Commerce, NIST, 1995 , p.1.

${ }^{9}$ Greenes, MD, PhD, Robert A., and Edward H. Shortliffe, MD, Ph.D. "Medical Informatics: An Emerging Academic Discipline and Institutional Priority." JAMA 263 (8, Feb. 23, 1990):1115.

10 "Health Security: The President's Report to the American People." The White House Domestic Policy Council, $1993,$. p. iii.

${ }^{11}$ For the first year of the focused programs eight program managers were tasked with developing focused programs. The number was influenced by the count, scope and expected potential impact of the white papers received in any one technology category.
} 
organized a small focus group followed by a public workshop attended by 400 representatives from industry, as well as the non-profit and academic communities. It was structured in a series of breakout sessions addressing the more relevant technological sub-domains identified in the white papers, e.g., information technologies, telemedicine and technology imaging. ${ }^{12}$ At the conclusion of the workshop, a representative from each session reported the group's findings to the entire body. From the resulting general discussion, a consensus developed, identifying infrastructural information technologies as offering the best means to achieve a significant reduction in healthcare costs while at the same time increasing quality of care. Two objectives accepted by the members of the workshop as constituting primary reasons for the establishment of a focused program in this particular area. Information technologies for healthcare also offered one of the most clearly defined areas of technological development requiring the public/private partnership offered by the ATP. The role of the ATP was thus defined as one of fostering cooperation and communication and serving as the catalyst needed to bring together the members of the information technology and medical communities to achieve the objectives.

The dialogue begun at the workshop between the program manager and healthcare industry consultants, representatives from non-profit healthcare organizations, healthcare professionals, and software development companies was sustained through the solicitation of additional white papers, both formal and informal, and through multiple small group discussions. ${ }^{13}$ The new white papers and additional interactions complemented the discussions held at the workshop, identifying the increased demands placed upon the U.S. healthcare industry to raise the quality of service, to extend consistent quality between rural and urban areas, to provide accurate measures of success, and to accomplish all of these with lower costs in a timely fashion while establishing national standards for the electronic transfer of patient records and related medical documents. This information, offering quite different notions of technological innovation in this area, fell into three distinct categories: a systems approach to an entire technological field; identification of a technological area purported to offer special promise for significant economic spillovers if "bottlenecks" are addressed; and, specific technical ideas that will, if supported, ultimately result in particular products.

Specific technologies identified in the IIH white papers included, but were not limited to, development of:

- Information tools to automate, validate and distribute clinical practice guidelines for mass use. These could include clinical practice guidelines that capture the current "best practices" for an array of medical situations. Their use by physicians and other healthcare professionals could potentially improve overall healthcare by reducing variations in treatment and the use of inappropriate procedures and treatments.

- The tools to enable healthcare providers and quality/cost monitors to browse and to extract data automatically from a multitude of scattered clinical and administrative databases, without requiring changes to the existing databases. This technology would enable the use of potentially valuable healthcare information which is often inaccessible due to the fact that most databases are isolated "pockets" of information, separated by diverse access programs and incompatible file and data formats.

\footnotetext{
${ }_{12}^{12}$ Advanced Technology Program, "Information Infrastructure for Healthcare (94-04)", U.S. Department of Commerce, NIST, 1994, p. 15.

${ }^{13}$ Additional white papers were received from workshop attendees as well as from those who responded to a solicitation for additional white papers posted by the program manager in the Commerce Business Daily (CBD).
} 
- Tools that facilitate the production of clinical notes and, as a byproduct, gather the codified clinical data and store it in a database system. This technology could lead to an automated coding system to support healthcare professionals in generating clinical notes of the patient's condition, treatment, and outcome, which could then be codified and stored in a database system for later retrieval and analysis.

- An interoperable open-systems architecture to serve as an interface between independent healthcare information systems. This infrastructure technology is crucial in addressing a central problem faced by many healthcare organizations, created by the need to work with a wide variety of existing healthcare and health management information systems, generally incompatible with each other, which have been created independently to serve the needs of various healthcare domains.

This input gave impetus to the final scope of the proposed focused program in the development of information infrastructure. As defined here, information infrastructure development includes: the integration, synthesis, and definition of any information that needs to be shared across the enterprise; and, the means by which to transport, store, and access that information in a way that enhances, rather than impedes, user productivity.

Based on all written and verbal communications of ATP Program Managers with the private sector and others, each of them was tasked with making a presentation before a selection board comprised of the Director and Associate Director of NIST and members of the ATP management team, addressing the four criteria: (1) potential for U.S. economic benefit; (2) good technical ideas; (3) strong industry commitment; and, (4) the opportunity for ATP funds to make a significant difference. ${ }^{14}$ Based on these criteria, it may be seen that a focused program has both technical and business goals. In May 1994, ATP announced funding in five focused programs, including the IIH Focused Program.

\section{Information Infrastructure for Healthcare Focused Program}

The ATP Information Infrastructure for Healthcare Focused Program solicitation kit identified the program's goals as follows:

\section{Technical Goals}

To establish the technologies for:

- Reliable storage and retrieval of complex medical information for varied applications;

- Real-time, data-driven medical decisions;

- Real-time data entry by mobile medical personnel;

- Real-time global transport of complex medical records with accuracy, speed, and security;

- Computer-based medical training, diagnostic, and reference tools.

\footnotetext{
${ }^{14}$ Program Idea Guide, Advanced Technology Program, U.S. Department of Commerce, NIST, May 1997, p. 3.
} 


\section{Business Goals}

To gain the capability to develop products that will:

- Reduce unit healthcare costs;

- increase productivity of healthcare providers by shifting time from paperwork to patient care,

- shorten hospital stays; reduce outpatient visits per illness;

- decrease needless duplication of records through reuse;

- decrease duplicative and erroneous tests;

- improve financial and management information handling.

- Improve quality of healthcare (higher treatment success rates and avoidance of complications);

- improved patient monitoring;

- faster and more accurate analysis of data;

- faster delivery of treatment;

- more accurate diagnosis;

- reduced incidence of errors in tests ordered;

- remote and widespread access to expert medical advice and advanced diagnostic and treatment tools.

- Capture global market share of new and improved products and services.

- Undertake infrastructural development focusing upon 'tools' and prototype systems to enhance the flow of information between existing 'legacy' systems in the healthcare enterprise while being scalable from a single provider's office to a fully integrated healthcare system. Infrastructural development is intended to enable enterprise-wide integration of information among all sectors of the healthcare industry and is expected to encompass the following:

- the integration, synthesis, and definition of any information which needs to be shared across the enterprise; and,

- he means by which to transport, store, and access that information in a way that enhances the productivity of the end-user." 15

A model of the program, which would result in a portfolio of required technologies, is presented in figure 1 in the form of a "pyramid" consisting of three categories, which should be read from bottom to top: (1) Infrastructure Development Technologies (e.g., tools for enterprise integration, business process modeling); (2) User Interface and Efficiency-Enhanced Technologies (e.g., hypermedia human interfaces, natural language processing, data retrieval \& advanced search mechanisms); and (3) Healthcare-Specific Technologies (e.g., clinical decision support systems, consumer health information and education systems). ${ }^{16}$ Each level is presented as being distinct from the next with the thought at the time being that development of those technologies in the lower levels should precede development of those above, resulting in a "bottom-up" approach. This logic influenced the announcement of the first and second solicitations whereby only those projects in which the high-risk technology development "fit" into the respective levels were to be

\footnotetext{
15 Advanced Technology Program, "Information Infrastructure for Healthcare (94-04)", U.S. Department of Commerce, NIST, 1994

${ }^{16}$ Ibid, p. 4 .
} 


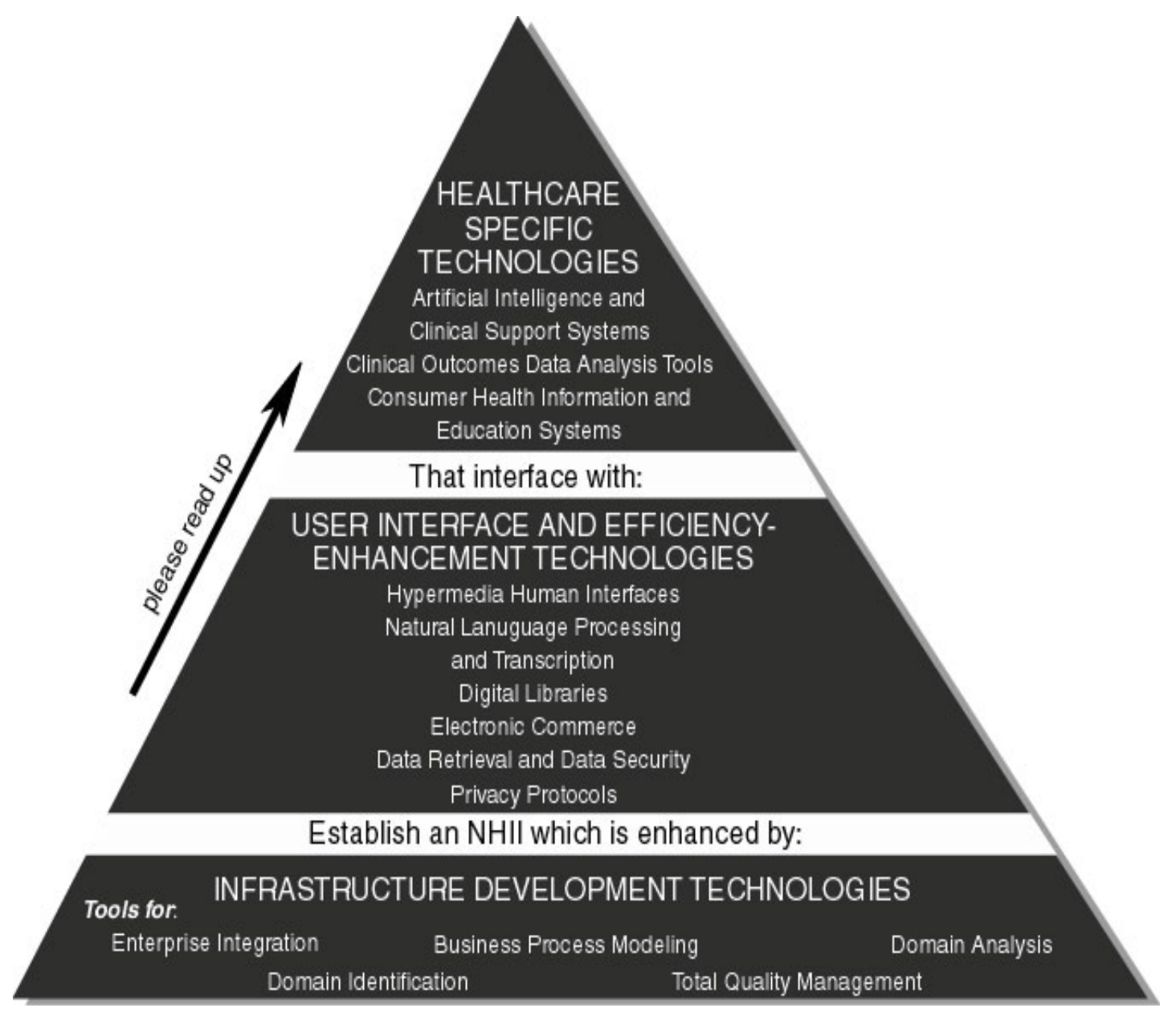

Figure 1 - Model of the IIH Program

funded. It was recognized, of course, that there is considerable overlap among the levels and that, therefore, components from more than one level may be proposed in any given project. Before the announcement of the third solicitation, it was recognized that technological R\&D in this industry requires additional and simultaneous development of "infrastructural" technologies along with those "higher" on the pyramid. In 1997, therefore, the third solicitation sought proposals that focused on the lower two levels of the pyramid but addressed all technologies in all levels.

\section{V. $\underline{\text { IIH Focused Program Project Selection Process }}$}

The ATP forms Source Evaluation Boards (SEBs) to review project proposals and make recommendations for funding. SEB membership is comprised solely of federal employees possessing technical and business expertise. In focused program competitions, proposals were first screened to determine if they were "within scope"17 and contained all of the necessary

\footnotetext{
${ }^{17}$ The concept of being "within scope" applies only to those proposals received through the focused programs. In the instance of the IIH focused program "within scope" carried an additional requirement of fitting into the portfolio of technologies specified in the solicitation kit.
} 
documentation, then those remaining received detailed technical and business reviews. For the focused programs operated during this time, the SEB was generally comprised of 8-10 people. SEB members receive advice provided by additional independent reviews from non-SEB members. Non-SEB "technical reviewers" are primarily scientists employed in federal labs chosen for their expertise in the selected technical area. Non-SEB "business reviewers" are professionals with business and economics expertise, including business executives whose careers were spent in the selected technical area, economists, venture capitalists, and business academics. All sign non-disclosure and non-conflict-of-interest forms.

With the full membership in attendance, or a pre-determined quorum, the members of the SEB discuss each proposal with attention to its conformance with both the technical and business criteria outlined in the ATP Application Kit. ${ }^{18}$ Those proposals determined to be within scope and possessing high technical and business merit against the criteria are placed in a semi-finalist category.

The ATP offers several means of communication with proposal writers. Pre-proposals, one to four pages in length, allow potential applicants an opportunity to submit a scaled-down version of what might become a more lengthy full proposal. ${ }^{19}$ Feedback from ATP regarding the preproposal helps businesses determine whether the project fits ATP's selection criteria and whether the proposed work is within the scope of the intended focused program. ${ }^{20}$ Optional pre-proposals can be submitted anytime and are reviewed as they are received. Detailed instructions for the submission of pre-proposals are outlined in the Proposal Preparation Kit. Companies are also free to submit full proposals whether or not they submitted a pre-proposal. All proposals are reviewed, and semi-finalists are invited by the SEB to attend an oral review in which they are asked to respond to a series of technical and business questions that address specific issues. Technical questions commonly focus on the "high technical risk" component of the proposal, while business questions are often centered on potential applications of the technology, on the need for ATP funding as opposed to private sector funding, on commercialization plans, company commitment, budgetary matters, and economic spillover potential. For those proposals not selected as semi-finalists, a telephone debriefing is offered upon request. ${ }^{21}{ }^{22}$ Semi-finalists who do not receive awards are offered a telephone debriefing. The debriefing is usually performed by both the technical and business "sponsors" 23 of a particular proposal.

Debriefings offer an opportunity for proposers to receive feedback from the ATP on shortcomings of their proposals that could be useful in rewriting a proposal for re-submittal. The debriefing might also be useful in gaining insights about the ATP selection criteria that might

\footnotetext{
${ }^{18}$ ATP Proposal Preparation Kit, U.S. Department of Commerce, NIST, November 1994. pp. 12-27. (updated annually) The ATP is an evolving program and changes have been made that alter the conditions and practices that were in place for the IIH Focused Program.

19 Proposals submitted by single applicants at the time of the first IIH Focused Program had a maximum page count of forty pages, those submitted by Joint Ventures had a maximum page count of fifty pages.

${ }^{20}$ The use of the pre-proposal was left to the discretion of the focused program manager in previous years and had been used only sparingly. (Pre-proposals were an option for the $1994 \mathrm{IIH}$ focused program solicitation). For the fiscal year, 1999 and 2000, “Open Competitions" preproposals were welcomed in all technology areas.

${ }^{21}$ Proposals not classified in the semi-finalist category may also include those screened out due to deficiencies in proper documentation and/or failure to fit within the technical scope of a particular focused program.

${ }^{22}$ Requests for debriefings can only be made during a limited period following notification from the ATP. ATP has followed the practice of providing one debriefing per proposal by telephone.

23 "Sponsors" are SEB members who are assigned responsibility to ensure that each proposal receives an impartial hearing. Each proposal is assigned to two SEB "sponsors. - a business sponsor and a technical sponsor.
} 
help in formulating an entirely new proposal to ATP, or in preparing a proposal for venture capitalists or other alternative sources of financing.

Upon completion of the oral reviews, the SEB presents a ranking of proposals to a Selecting Official who is charged with making funding recommendations to the ATP Director. At this point the Selecting Official may request clarification from the SEB regarding the final ranking. The ATP Director makes the ultimate funding decision. ${ }^{24}$

\section{IIH Focused Program Awardees ${ }^{25}$}

Table 1 below provides summary statistical data from the three IIH solicitations held between 1994 and 1997, in which 221 proposals were received and 32 awards were made to 79 participants. R\&D funding totaled $\$ 295$ million, representing a commitment of \$146 million from the government and $\$ 149$ million from the private sector.

Table 1: IIH Focused Program Participation

\begin{tabular}{|l|c|c|c|}
\hline & $\mathbf{1 9 9 4}$ & $\mathbf{1 9 9 5}$ & $\mathbf{1 9 9 7}$ \\
\hline Total Number of Proposals Submitted $^{\boldsymbol{\dagger}}$ & 59 & 68 & 94 \\
\hline Total Number of Projects Funded & 16 & 10 & 6 \\
\hline Type of Award Participant & 10 & 7 & 6 \\
Single Applicant & 6 & 3 & \\
Joint Venture & & & \\
& & & \\
\hline Total Number of Participants & 43 & 32 & 6 \\
& & & \\
\hline Type/Size of Organization* & & & \\
PS (For-Profit Small Company) & 17 & 12 & 6 \\
PM (For-Profit Medium Company) & 6 & 4 & \\
PL (For-Profit Large Company) & 6 & 5 & \\
NP (Non-Profit) & 7 & 8 & \\
U (University) & 4 & 3 & \\
\hline
\end{tabular}

24 In the early days of the ATP the NIST Director made the final decision.

25 The statistical data included in the tables and charts that follow are from the Business Reporting System (BRS) database maintained by the ATP Economic Assessment Office. Begun in 1994, the BRS provides a comprehensive data tool used for tracking purposes on a routine and regular basis and for measuring progress of projects against business plans and projected economic benefits as outlined in the project proposals and updated over the course of the projects.

t "A single for-profit company may apply, as well as a joint venture with at least two separately owned for-profit companies, both of which are substantially involved in the R\&D and both contributing towards the matching-fund requirement. The joint venture need not be a legally constituted entity. Most ATP joint ventures consist of companies who simply agree to collaborate on the R\&D and divide the tasks and often contain potential end users. Single company recipients can receive ATP funds for R\&D activities for up to 3 years, with ATP funding not to exceed $\$ 2$ million for direct costs. Joint ventures, however, can receive ATP funds for R\&D activities for up to 5 years, with ATP funding a minority share of the yearly total project costs. Joint ventures must cost-share (matching funds) more than 50 percent of the total project costs (direct plus indirect costs) for each quarter that the ATP funds the project. Large companies applying as single applicants, must cost-share at least 60 percent of the yearly total project costs (direct plus indirect costs) Advanced Technology Program Proposal Preparation Kit, November 1999 , p. 3.

"The number of participants presented here does not include sub-contractors.

* "Small" companies are defined as having fewer than 500 employees. "Large" companies are defined as "Fortune 500" or equivalent companies. "Medium" companies are defined as all others. 
The number of awards are listed by Single Applicant (SA) or Joint Venture (JV), number of participants, and type and size of organization. The first competition, held in 1994, resulted in awards to 10 SA's and 6 JV's encompassing a diverse collection of for-profit and non-profit companies. This pattern was repeated when the second competition was held in 1995, but there was a downturn in the number of awards. The third competition, held in 1997, resulted in awards only to small for-profit companies. The decline in the number of awards in 1995, and more noticeably in 1997, is mainly attributable to the decrease in the total dollar amounts that were available. ${ }^{26}$ During this period there was an increase in the number of proposals submitted. The lack of awards to joint ventures in 1997 may be explained by the high degree of uncertainty over the Federal budget and the fact that the solicitation announcement could not occur until the Congress had finalized the ATP appropriation. ${ }^{27}$

What remains relatively constant across the three solicitations is a dominant role of small forprofit companies (PS). These companies participated both as SA's and as members of JV's. Single applicant award recipients included start-ups as well as research organizations in medium and large size companies. The JV's consisted of several types of organizations of varying size and scale, and with different orientations to technology development. They include a diverse group of large and small companies, non-profit organizations, and universities. In some instances, competitors joined to overcome rather complex technical issues. Also, the IIH focused program encouraged the creation of collaborations among computer and medical professionals and organizations to enhance the development of needed technologies, and to, "... help the healthcare industry avoid 'fragmentation'."

Analysis of the projects resulting from the IIH competitions will illustrate the broad range both of the technology areas funded within a focused program and of the subsequent applications of those technologies. Several specific projects will be discussed as examples.

\section{VII. $\underline{\text { IIH Technologies }}$}

ATP funds technology development projects that often consist of sets of related projects involving an interdisciplinary mix of science and technology fields. In analyzing technologies funded, ATP uses its own hierarchical classification system to identify technology areas under development by different organizations and projects. Individual companies self select primary and secondary codes which best describe their areas of R\&D. ${ }^{28}$ Figure 2 summarizes the technologies funded through the ATP Focused Program according to their first level code assignments.

\footnotetext{
${ }^{26}$ The amount of funding available for the first IIH competition was up to $\$ 30 \mathrm{M}$, with up to $\$ 20 \mathrm{M}$ available for the second competition and up to $\$ 15 \mathrm{M}$ for third.

${ }^{27}$ When the budget issue for fiscal year 1997 was resolved there was a relatively short period of time in which to announce the 97-10 competition and establish a project proposal submission deadline. Joint Ventures are rather complex organizations which require a significant period of time to arrange.

${ }^{28}$ This information is collected annually through the BRS and may change as the project matures.
} 
Figure 2. Number of IIH Focused Program

Technologies Under Development

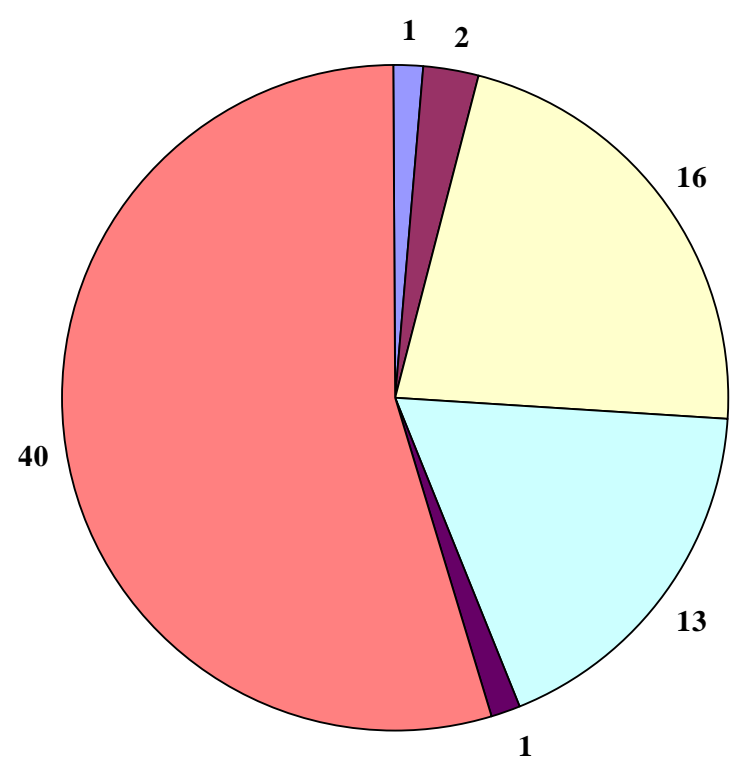

$\square 20 \square 23 \square 24 \square 26 \square 28 \square 29$

20 = Computer Software; 23 = Pattern Recognition; 24 = Networking/Communication; 26 = Component-based Programming; 28 = Computer-aided Instruction; 29 = Systems Modeling and Integration

A joint venture led by the Advanced Technology Institute (ATI)--formerly the South Carolina Research Authority (SCRA) ${ }^{29}$--offers the opportunity to view one example of the R\&D undertaken in the most frequently selected technology classification code, "Systems Modeling and Integration" (29). The project pursued, simultaneously, four major healthcare information infrastructure tasks, tying the results together through a central Open Systems Laboratory (OSL) to provide an independent laboratory in which technology developers can test, demonstrate, and evaluate the operation and interoperability of their systems. The four tasks included:

- enterprise connectivity solutions; tools to support exchange of electronic transactions between healthcare providers' offices and the payers, clinical services groups, suppliers, and other trading partners of a healthcare community. These tools will provide a significant reduction in the cost and time required for healthcare trading partners to initiate and maintain electronic commerce:

- distributed, rural, and remote diagnostics; tools to provide simple, controlled access through a central vocabulary to distributed patient clinical information, evidence-based practice guidelines, and clinical trials protocols. These tools will facilitate building healthcare information networks.

- healthcare enterprise information management; tools to improve productivity by linking components providing information management, process management, and vocabulary

\footnotetext{
${ }^{29}$ ATP project \#94-04-0004.
} 
support. These tools will provide decision makers with the information they need and will improve productivity and resource utilization through decision support tools.

- community services outreach; tools to provide scalable hardware and software solutions to support seamless delivery of integrated health and social services throughout a community.

The multidisciplinary team assembled by The Koop Foundation for the HOLON ${ }^{30}$ project (Health Object Library ON-line) provides a good example of the second most frequently chosen classification code, "Networking/Communication" (24). This joint venture, funded in 1995, was formed to create a "framework" for critically important "middleware," or networking software that connects user applications on one end with large, diverse knowledge bases and databases on the other. The project offered the development of a general architecture that specifies the organization, functions, and interfaces necessary for healthcare middleware, and a library of reusable objects to support companies in developing healthcare applications and integrating existing (legacy) systems into the new architecture. The object-oriented architecture development entailed the definition and implementation of multimedia healthcare domain objects that serve as the basic integrating components. The HOLON toolset developed includes software to aid in building "wrappers" to interface existing systems to the new architecture, naturallanguage interfaces to the system, advanced data search and synthesis applications, in particular, intelligent agents that can anticipate user needs, and tools for translating information to match the display capabilities of the user's device, so that everything from a powerful workstation to a hand-held PDA can access HOLON resources.

The technology development proposed by Sunquest Information Systems ${ }^{31}$ provides a good example of the third most frequently chosen classification code, "Component-based Programming" (26). Awarded in 1995 as a single applicant, Sunquest Information Systems proposed the development of decision support system that would acquire information from the large body of unstructured information in healthcare (i.e., text, word processor files, discharge summaries, radiological reports, pathology reports, admission histories) and integrate this with more structured data such as the clinical data and laboratory reports to create a real-time support system. To facilitate this an automated vocabulary system was proposed to map key terms onto a unified "concept identifier." Also, expert-system techniques were developed to map the information into a knowledge base, where it can be analyzed and used as a basis for decision support systems and to issue alerts, for example, on patients whose data profiles suggest the need for some additional action.

From the sample descriptions above, it is clear that many of the projects can easily be categorized in more than one technology area. This, and the concentration of projects under the technology code classifications in figure 1 , reflect the infrastructural nature of the program.

\footnotetext{
30 ATP project \#95-10-0067.

31 ATP project \#95-10-0008.
} 


\section{Technology Applications}

Data collected through the BRS provides information regarding the potential use of the developed products. Award recipients are requested to provide the SIC codes of those sectors of the economy in which they believe their products would most likely be applied. For the 32 awarded projects in the IIH focused program 125 potential applications were identified and are illustrated in Figure 3.

Figure 3: Plans for Applications of ATP-Funded Technologies

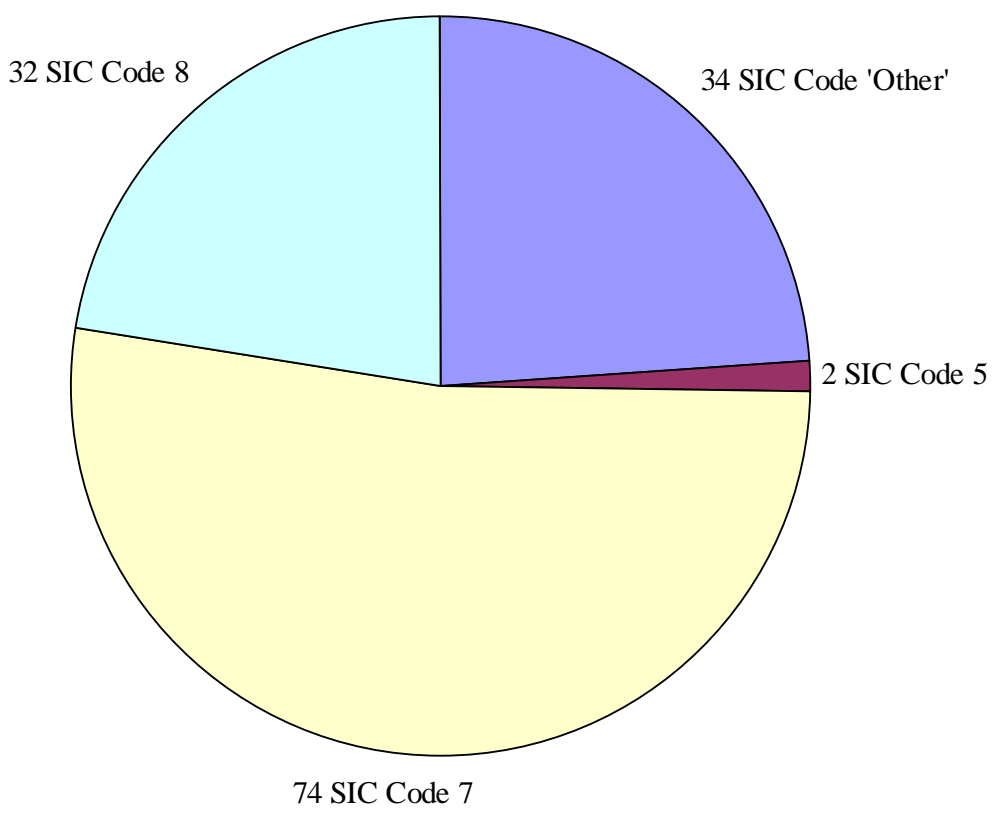

SIC code $5=$ Computers; SIC code $7=$ Business Services; SIC code $8=$ Health Services

SIC code 7 (Business Services) was selected by those companies planning to use their technology in this area at a rate twice that of all other SIC codes, reflecting the general nature of this category in capturing most of the technologies developed under the IIH focused program. Its selection may also be indicative, however, of the importance attached to the automation of administrative tasks in the healthcare industry, one of the first targets of opportunity for improvement recognized by the ATP efforts.

This selection also underscores the "enabling" characteristics of these technologies, since it suggests that applications can and will ensue in more industrial sectors. 
The joint venture project led by Allegheny-Singer Research Institute, ${ }^{32}$ funded as a result of the 1995 competition, provides an opportunity to observe some of the technologies developed under the category of Business Services. Other members of the joint venture include NCR Human Interface Technology Center, AT\&T Government Markets, NCR Data Warehouse Solutions Division, and Millennium Healthcare Solutions, Inc. The project focuses on the development of technologies for a networked medical knowledge bank that creates: central repositories for complex medical information; diagnostic indicators; details of preferred treatments or surgical procedures resulting in treatment guidelines. Accessible over wide-area computer networks, the knowledge banks will also provide the equivalent of 24-hour access to world-class consultants in an array of medical specialties. The project includes the development of a multimedia repository that can archive, browse, retrieve, index and search not only text data but still images, and video and audio data. Other facets of the project include development of indexing and searching methods for video data and medical case data, development of a case-based reasoning algorithm to recognize similarities between new medical cases and previously-stored cases, development of massively parallel multimedia database technology capable of handling petabytes of data, and development of an appropriate user interface to the registry to meet physicians' needs.

As mentioned earlier, ATP seeks broadly enabling technology. Health Services (SIC code 8) is a more specific classification of the application of technologies developed under the IIH focused program and one would rightfully expect this category to be smaller than the Business Services SIC code. By choosing this classification, however, companies do not preclude the possibility that their technologies could find applications in other sectors of the economy. One example is Belmont Research, Inc., ${ }^{33}$ a company funded in 1994 as a single applicant proposing to develop the necessary tools to build a network browser and data collector that would give healthcare workers simple and transparent access to heterogeneous databases without requiring changes to the databases themselves. The medical database browser will process the formats and commands of--and retrieve data from--the various heterogeneous databases it deals with without requiring changes to those systems. It will also support an ability to pose queries to remote databases and to receive the information in a format that can be further manipulated, while providing for data integrity, security, and patient confidentiality. In addition to the core applications in healthcare, the company has identified a number of other markets in which complex information must be gathered from multiple sources for data analysis including discrete and continuous manufacturing, telecommunications, and financial services.

\section{New Format for Proposal Solicitation, Review, and Selection}

As discussed previously, beginning with fiscal year 1999, the ATP merged the concept of focused program competitions and general competitions, resulting in an "open" format, combining the best features of previous competition models. Under an open competition a proposal selected for funding that is synergistic with an existing focused program is managed under that program. In other cases proposals developing complementary technologies that form a critical mass are "bundled"

\footnotetext{
32 ATP project \#95-10-0030.

33 ATP project \#94-04-0024.

34 The "bundling" of proposals for the purpose of creating a "virtual" focused program will only occur when a critical mass of proposals in a shared domain has been achieved. Any proposal that does not fall within an announced or virtual focused program is managed independently .
} 
manner similar to that of announced focused programs. In the case of healthcare informatics, proposals which in the past would have been submitted under the IIH Focused Program competition are now directed towards the Information Technology SEB. Those proposals selected for funding will be administered as part of the IIH Focused Program. ATP continues to work with industry and other organizations to define and update current challenges and opportunities in medical informatics.

Companies wishing to submit proposals which address elements of any of the three tiers of the pyramid (see figure 1) developed under the existing IIH focused program may still do so. Alternatively, companies may wish to submit proposals offering innovative solutions to those technical challenges outlined in the white paper authored jointly by ATP and industry titled, "Initiatives in Healthcare Informatics," and accessible on the ATP web site. New technical areas not addressed in either the IIH Focused Program, or in the white paper, or in other ATP focused program areas are also encouraged. All proposals submitted to the ATP will be evaluated solely for their scientific and technological merit and their potential for broad-based economic benefits, with parts weighted equally. No longer is there a need to determine whether a proposal falls within the scope of a specific technical program.

The introduction of this new Open Competition is part of an on-going process on the part of the ATP to improve upon its operations, in this case by offering a vehicle by which industry may respond more quickly to common barriers and opportunities without the delay brought about by the development of a focused program. ${ }^{35}$

\section{Conclusions}

The ATP IIH Focused Program has contributed significantly to accelerating the development of infrastructural tools as well as the user interface and efficiency-enhancement technology necessary for a National Information Infrastructure for Healthcare. It has encouraged their development from the "bottom up" rather than imposing them in a "top down" fashion, which could have resulted in restrictions on the types of technologies developed. The driving force behind these advances remains the development of open, interoperable, yet secure systems-systems that will provide the medical community with the capability to integrate diverse information and business systems as well as the data necessary to support continuous quality improvement, thus addressing several primary issues of critical importance in today's delivery of healthcare.

The IIH Focused Program has also acted as a catalyst in establishing collaborations bringing together the stakeholders and providing the opportunity to pursue cross-disciplinary projects, with participation from healthcare providers as well as computer scientists and information technology specialists. In several cases the collaborations that were formed included companies that never had nor, under ordinary circumstances, never would have worked together.

\footnotetext{
${ }^{35}$ Developing a focused program often encompasses a one-to-two year period. A program manager is assigned to a particular industrial sector in response to industry needs and asked to define whether or not ATP has a role. Current focused programs were designed with a finite time horizon. Those programs which were scheduled for multi-year competitions were intended to complete a body of work as established in the program definition or as modified due to changes in the technology environment. Both developing a new focused program and modifying an existing one were lengthy, laborious processes.
} 
These efforts have led to a reduction in the likelihood of closed systems and have increased industry entry opportunities for small to medium-sized companies. For the end-user, this program has accelerated market acceptance and enabled industry to improve medical care while lowering costs.

Today, with rapid changes in both technology and in the delivery of healthcare, there are new challenges in healthcare informatics research. The Advanced Technology Program provides an excellent vehicle by which for government-industry partnerships in this domain will accelerate the development of high-risk technologies with promise of significant commercial payoffs and widespread benefits for the economy.

\section{References}

1. Blum, Bruce I. and Karen Duncan, eds., A History of Medical Informatics, Addison Wesley, Reading, MA (1990).

2. Etzkowitz, Henry, Andrew Webster, and Peter Healey (eds.), Capitalizing Knowledge: New Intersection of Industry and Academia, State University of New York Press, Albany, New York (1998).

3. Greenes, Robert A., MD, PhD, and Edward H. Shortliffe, MD, PhD, Medical Informatics: An Emerging Academic Discipline and Institutional Priority, JAMA 263 (8, Feb. 23):1114 (1990).

4. Health Security: The President's Report to the American People, The White House Domestic Policy Council (1993).

5. National Science Foundation, Comparing National Efforts at Technological Foresight, Science Indicators. Chp. 6. National Science Foundation, Arlington, VA 1998.

6. Shortliffe, Edward H., and Leslie E. Perreault, (eds.), Medical Informatics, Addison-Wesley, Reading, MA (1990).

7. U.S. Department of Commerce, National Institute of Standards and Technology, ATP Proposal Kit, November 1999.

8. U.S. Department of Commerce, National Institute of Standards and Technology, Advanced Technology Program, Information Infrastructure for Healthcare (94-04; 95-10; 97-03), 1994, 1995, 1997.

9. U.S. Department of Commerce, National Institute of Standards and Technology, Advanced Technology Program, Program Idea Guide, May 1997.

10. Winfree, Robert G., Jane G. Elchlepp, and Willliam Stead, Centrally Guided Distributed Information Systems: The Next Step, Healthcare Information Management Systems, Springer-Verlag, New York (1991). 


\section{About the Advanced Technology Program}

The Advanced Technology Program (ATP) is a partnership between government and private industry to conduct high-risk research to develop enabling technologies that promise significant commercial payoffs and widespread benefits for the economy. The ATP provides a mechanism for industry to extend its technological reach and push the envelope beyond what it otherwise would attempt.

Promising future technologies are the domain of the ATP:

- Enabling technologies that are essential to the development of future new and substantially improved projects, processes, and services across diverse application areas;

- Technologies for which there are challenging technical issues standing in the way of success;

- Technologies whose development often involves complex "systems" problems requiring a collaborative effort by multiple organizations;

- Technologies which will go undeveloped and/or proceed too slowly to be competitive in global markets without the ATP.

The ATP funds technical research, but it does not fund product development. That is the domain of the company partners. The ATP is industry driven, and that keeps it grounded in real-world needs. For-profit companies conceive, propose, co-fund, and execute all of the projects cost-shared by the ATP.

Smaller companies working on single-firm projects pay a minimum of all the indirect costs associated with the project. Large, "Fortune-500" companies participating as a single firm pay at least 60 percent of total project costs. Joint ventures pay at least half of total project costs. Single-firm projects can last up to three years; joint ventures can last as long as five years. Companies of all sizes participate in ATP-funded projects. To date, more than half of the ATP awards have gone to individual small businesses or to joint ventures led by a small business.

Each project has specific goals, funding allocations, and completion dates established at the outset.

Projects are monitored and can be terminated for cause before completion. All projects are selected in rigorous competitions which use peer-review to identify those that score highest against technical and economic criteria.

Contact the ATP for more information:

- On the World Wide Web: http://www.atp.nist.gov;

- By e-mail: atp@ nist.gov;

- $\quad$ By phone: 1-800-ATP-FUND (1-800-287-3863);

- By writing: Advanced Technology Program, National Institute of Standards and Technology, 100 Bureau Drive, Stop 4701, Gaithersburg, MD 20899-4701.

\section{About the Authors}

Bettijoyce B. Lide is the Program Manager for the ATP program, Information Infrastructure for Healthcare, and has been with the Advanced Technology Program since its inception in 1990. Before that she was the Group Leader of the Data Systems Development Group, National Standard Reference Data System, and was active in national and international efforts in the computerization of chemical and physical data.

Dr. Richard N. Spivack has been with the Advanced Technology Program (ATP) since 1994 where he is a member of the Economic Assessment Office. Dr. Spivack divides his time between undertaking research into the ATP's long-term economic impacts upon the U.S. economy and serving as both the business chair and project manager in the Information Infrastructure for Healthcare focused program. Dr. Spivack received his Ph.D. in Economics from the University of Connecticut. 